\title{
Political Regime and Suspected COVID-19 Death Data Manipulation*
}

\author{
Susumu Annaka \\ Waseda University
}

October 18,2020

\begin{abstract}
The COVID-19 pandemic — the worst one since the Spanish flu—has dramatically

changed the world, with a great number of people still suffering and dying from the dis-

ease. Some scholars argue that the pandemic has severely damaged democratic coun-

tries, mainly because these cannot intervene in their citizens' lives, as opposed to their

authoritarian counterparts. Another study challenges this view and suggests that authoritarian countries manipulate data on COVID-19-related deaths. This paper aims to determine which view is more persuasive using cross-national data. This article uses statistical evidence to reveal that authoritarian countries are likely to manipulate the data. The result implies that, with this successful manipulation, authoritarian states can strengthen citizens' support for their governments through the COVID-19 pandemic.
\end{abstract}

* I wish to thank Masataka Harada (Fukuoka University), Masaaki Higashijima (Tohoku University), Kentaro Hirose (Waseda University), and Masaru Kohno (Waseda University) for their helpful comments. 


\section{Introduction}

The number of COVID-19 deaths is reported to exceed one million all over the world.

Some argue that people, especially in democratic countries, face a tradeoff between

freedom and health (Harari 2020; Koyama 2020). Recently published papers also reveal that democratic countries suffer from COVID-19 deaths more than authoritarian states (Cepaluni et al. 2020; Cheibub et al. 2020). Graph 1 supports these arguments to some extent. It shows the number of COVID-19 deaths on the vertical axis as reported by Johns Hopkins University and the level of Polity2 on the horizontal axis from the Polity V Project. ${ }^{1}$ The number of deaths is the total sum since the first confirmed cases were reported (as of July 31, 2020). The correlation coefficient between the two variables is 0.2680 , and it is statistically significant at the $1 \%$ level. This moderate positive relationship suggests that the arguments should be correct. However, is this relationship truthful? This article attempts to answer this question.

\footnotetext{
${ }^{1}$ The Center for Systems Science and Engineering (CSSE) at Johns Hopkins Un iversity (2020) COVID 19 Data Repository, https://github.com/CSSEGISandData/ COVID19, accessed on August 8, 2020, Marshall, M. G., Jaggers, K., and Gurr, T. R. (2020) Polity V Project, Political Regime Characteristics and Transitions, 1800-2018. Center for Systemic Peace, http://www.systemicpeace.org/inscrdata.ht ml, accessed on August 8, 2020.
} 


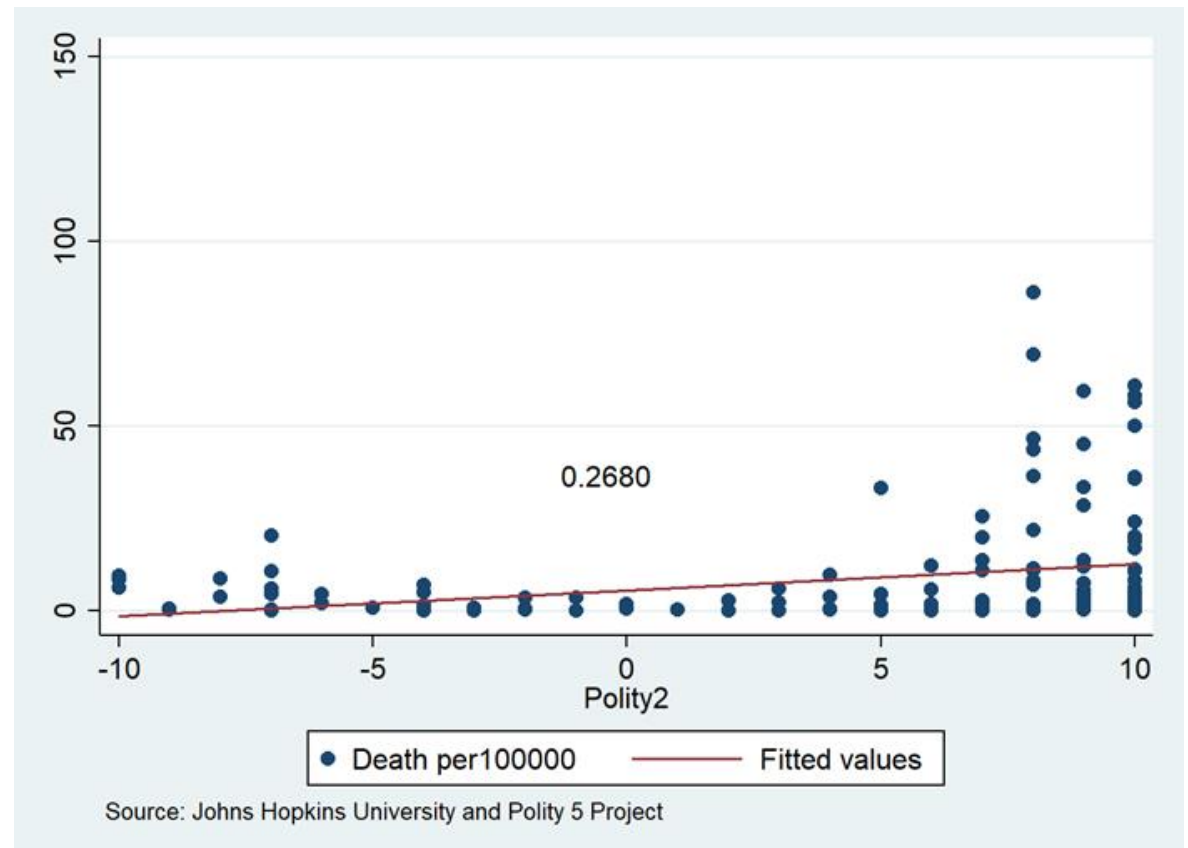

Graph 1: Relationship between Polity2 and the Number of COVID-19 Deaths

Why can these arguments be questioned? For example, it is reported that Alexander Lukashenko, the Belarusian President, underestimated the risk for COVID-19 spreading across the country. The president did not take any appropriate measures to prevent the pandemic in the country. As this case implies, authoritarian governments do not necessarily take a decisive measure immediately. However, the country has one of the lowest death rates in Europe (Karáth 2020). This is incredible. If the COVID-19 confirmed cases in authoritarian countries are not reduced, the argument that the government's intervention can reduce COVID-19 deaths by reducing confirmed cases is not persuasive. 
In another case, Cepaluni et al. (2020) show a statistical analysis in which political regime is positively correlated with COVID-19 deaths. Their analysis includes confirmed cases as a control variable, which is also positively correlated with COVID19 deaths, as expected. As it is puzzling that the political regime variable is statistically significant even after controlling for the confirmed cases, this leads to the question above. It is often argued that, if authoritarian governments can reduce death cases by stringent intervention, the total confirmed cases must be reduced first; however, the statistical analysis shows a significant effect of political regime on deaths, even after controlling for the confirmed cases. This result implies that a factor other than the confirmed cases significantly affects COVID-19 deaths in authoritarian countries.

It is difficult to imagine that the medical system in authoritarian states can work better than that in democratic countries. Scholars have highlighted that people in democratic countries are likely to have better health than their authoritarian counterparts (Wang et al. 2020; Gerring et al. 2020). Another possibility is that authoritarian countries manipulate death data. Kapoor et al. (2020) analyze the data's moving average and reveal that the data are unnaturally produced. This paper aims to determine which view is more persuasive using cross-national data. 


\section{Determinants of Confirmed Cases and Non-Pharmaceutical Interventions}

First, this study considers the determinants of confirmed cases and non-pharmaceutical interventions (NPIs) — such as lockdowns_-by utilizing data from the Johns Hopkins University and the University of Oxford (Hale et al. 2020) before analyzing the effect of political regime on COVID-19 deaths. If authoritarian governments can reduce COVID19 deaths by reducing the number of confirmed cases, it must be through stringent interventions in people's lives. Here, simple statistical analyses are conducted to test this relationship.

This study utilizes cross-national data on over 100 countries. The dependent variables are COVID-19 confirmed cases and NPIs operationalized by the Stringent Index (Hale et al. 2020). These variables record the daily change of the confirmed cases and a government's response to the pandemic. However, almost all other covariates necessary to be included in the analysis are yearly data, such as GDP per capita. This study constructs cross-sectional data for all statistical analyses below. The confirmed cases and Stringent Index are averaged by each country until July 31, 2020.

Political regime variables are obtained from the Polity Project and Variety of Democracy (V-Dem) Project. ${ }^{2}$ Control variables such as GDP per capita, trade ratio to

2 Coppedge, M., Gerring, J., Knutsen, C.H., Lindberg, S. I., Teorell, J., Altman, D., Bernhard, M., Fish, M. S., Glynn, A., Hicken, A., Luhrmann, A., Marquardt, K.L., McMann, K., Paxton, P., Pemstein, D., Seim, B., Sigman, R., Skaaning, S., Staton, J., 
GDP, total population, population density, and population ratio age 65 and above are taken from the World Bank. ${ }^{3}$ The latitude, the days since the first confirmed case was reported, and the number of total confirmed cases are also obtained from Johns Hopkins University. The latest available yearly data are used. The models take the logs of the variables (except for latitude and days since the first confirmed case) to consider skewed distributions. The descriptive statistics are presented in Appendix 1. The analysis of the confirmed cases uses Negative Binomial regression to consider the dependent variable's skewed distribution. Ordinary Least Square regression is applied for the analysis of the Stringent Index. Table 1 shows the results of the regression results for the determinants of the confirmed cases.

Model 1 is the result of the relationship between Polity 2 from the Polity Project and confirmed cases. The result shows that Polity2 is not statistically significant. GDP, trade, and population are significant. Model 2 analyzes the relationship between the Polyarchy Index from the V-Dem Project and confirmed cases. This model shows almost

Wilson, S., Cornell, A., Alizada, N., Gastaldi, L., Gjerløw, H., Hindle, G., Ilchenko, N., Maxwell, L., Mechkova, V., Medzihorsky, J., Sundström, J. A., Tzelgov, E., Wang, Y., Wig, T., and Ziblatt, D.. 2020. "V-Dem [Country-Year/Country-Date] Dataset v10". Varieties of Democracy (V-Dem) Project. https://doi.org/10.23696/vdemds20.

3 World Development Indicators, http://datatopics.worldbank.org/world development indicators/, accessed on August 8, 2020. 
the same results as model 1 . These results suggest that the political regime variables do not affect the COVID-19 confirmed cases.

Table 1: Determinants of Confirmed Cases

\begin{tabular}{|c|c|c|}
\hline & (1) & (2) \\
\hline & NB & NB \\
\hline VARIABLES & Confirmed Cases & Confirmed Cases \\
\hline \multirow[t]{2}{*}{ Polity2 } & 8,106 & \\
\hline & $(7,518)$ & \\
\hline \multirow[t]{2}{*}{ Polyarchy } & & 142,960 \\
\hline & & $(193,125)$ \\
\hline \multirow[t]{2}{*}{ GDP (log) } & $89,921^{* *}$ & $80,086 * *$ \\
\hline & $(37,918)$ & $(37,302)$ \\
\hline \multirow[t]{2}{*}{ Trade (log) } & $-186,479 *$ & $-190,563 * *$ \\
\hline & $(97,954)$ & $(92,414)$ \\
\hline \multirow[t]{2}{*}{ Population (log) } & $105,539 * * *$ & $89,744 * * *$ \\
\hline & $(36,017)$ & $(32,371)$ \\
\hline \multirow[t]{2}{*}{ Population Density (log) } & $-25,537$ & $-18,064$ \\
\hline & $(27,156)$ & $(25,290)$ \\
\hline \multirow[t]{2}{*}{ Age 65 and above (ratio) } & $-56,097$ & $-31,522$ \\
\hline & $(80,122)$ & $(76,109)$ \\
\hline \multirow[t]{2}{*}{ Latitude } & 187.8 & -395.1 \\
\hline & $(1,757)$ & $(1,642)$ \\
\hline \multirow[t]{2}{*}{ Days since the first confirmed case } & 523.8 & 868.7 \\
\hline & $(2,622)$ & $(2,541)$ \\
\hline \multirow[t]{2}{*}{ Constant } & $-1.493 e+06 *$ & $-1.281 e+06^{*}$ \\
\hline & $(823,161)$ & $(754,047)$ \\
\hline Observations & 141 & 147 \\
\hline R-squared & 0.248 & 0.237 \\
\hline
\end{tabular}

Table 2 shows the results of the regression results for the determinants of the

NPIs. Model 3 is the result of the relationship between Polity2 from the Polity Project and Stringent Index. The result shows that Polity2 is not statistically significant. The other variables, except confirmed cases, are also not significant. Model 4 analyzes the relationship between the Polyarchy Index from the V-Dem Project and Stringent Index. This model shows almost the same results as model 3 . These results suggest that 
confirmed cases in each country affect the government's responses to COVID-19, regardless of other factors such as political regime. This implies that authoritarian governments do not necessarily intervene in civil society more than democratic states. ${ }^{4}$

Table 2: Determinants of Stringent Index

\begin{tabular}{|c|c|c|}
\hline & (3) & (4) \\
\hline & OLS & OLS \\
\hline VARIABLES & Average SI & Average SI \\
\hline \multirow[t]{2}{*}{ Polity2 } & -0.0666 & \\
\hline & $(0.1730)$ & \\
\hline \multirow[t]{2}{*}{ Polyarchy } & & -4.8990 \\
\hline & & $(4.4310)$ \\
\hline \multirow[t]{2}{*}{ GDP (log) } & -0.6740 & -0.5560 \\
\hline & $(1.0330)$ & $(1.0060)$ \\
\hline \multirow[t]{2}{*}{ Trade (log) } & -0.9670 & -0.9940 \\
\hline & $(2.2610)$ & (2.1370) \\
\hline \multirow[t]{2}{*}{ Population (log) } & -1.3790 & -1.4400 \\
\hline & $(0.9920)$ & $(0.9160)$ \\
\hline \multirow[t]{2}{*}{ Population Density (log) } & 0.1920 & 0.4470 \\
\hline & $(0.6240)$ & $(0.5810)$ \\
\hline \multirow[t]{2}{*}{ Age 65 and above (ratio) } & -2.0100 & -1.0940 \\
\hline & $(1.8750)$ & $(1.7710)$ \\
\hline \multirow[t]{2}{*}{ Latitude } & -0.0413 & -0.0578 \\
\hline & $(0.0407)$ & $(0.0380)$ \\
\hline \multirow[t]{2}{*}{ Days since the first confirmed case } & 0.0755 & 0.0699 \\
\hline & $(0.0607)$ & $(0.0590)$ \\
\hline \multirow[t]{2}{*}{ Confirmed cases (log) } & $2.232 * * *$ & $2.209 * * *$ \\
\hline & $(0.5430)$ & $(0.5280)$ \\
\hline \multirow[t]{2}{*}{ Constant } & $51.78 * * *$ & $52.81 * * *$ \\
\hline & $(19.78)$ & $(18.18)$ \\
\hline Observations & 141 & 147 \\
\hline R-squared & 0.1980 & 0.2050 \\
\hline
\end{tabular}

\section{Determinants of COVID-19 Deaths and Data Manipulation}

If authoritarian governments do not make stricter interventions in their citizens' daily

lives to combat COVID-19 compared to democratic governments, why do authoritarian

4 This analysis does not consider how swiftly the government responds, which may make a difference (Cepaluni et al. 2020; Cheibub et al. 2020). 
countries have fewer COVID-19 deaths? In this section, this riddle is examined-once again through statistical analysis.

The dependent variable is the number of COVID-19 deaths. The control variables are almost the same as the previous analysis above, except for an additional variable - the number of physicians per 1000 population from WDI data. This analysis uses negative binomial regression. Models 5 and 6 in Table 3 analyze the relationship between the political regime and COVID-19 deaths. Model 5 shows that Polity2 is positively correlated with COVID-19 deaths, and the coefficient is statistically significant even after controlling for the number of confirmed cases. This result suggests that the more democratic a country is, the more deaths it suffers. Model 6 shows the result from Polyarchy and almost the same as Model 5. These results are consistent with those of Cepaluni et al. (2020).

If authoritarian countries cannot reduce COVID-19 deaths by reducing the number of confirmed cases, why are fewer deaths registered in those countries? Is the medical system in authoritarian states better than that in democratic countries? A study suggests that Belarus, one of the authoritarian countries, has a large hospital capacity, leading to a lower death rates (Karáth 2020). That may be possible. However, the results of this study show the robust significance of the political regime variables on average even 
after controlling for the number of physicians. Moreover, People in democratic countries tend to have better health than those in authoritarian counterparts (Wang et al.

2019; Gerring et al. 2020), and it is peculiar that COVID-19 is an exception.

Table 3: Determinants of COVID-19 Deaths

\begin{tabular}{|c|c|c|}
\hline & (5) & (6) \\
\hline & NB & NB \\
\hline VARIABLES & Death Cases & Death Cases \\
\hline \multirow[t]{2}{*}{ 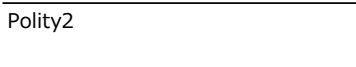 } & $0.0482 * * *$ & \\
\hline & $(0.0146)$ & \\
\hline \multirow[t]{2}{*}{ Polyarchy } & & $0.905^{* *}$ \\
\hline & & $(0.3860)$ \\
\hline \multirow[t]{2}{*}{ Physicians (log) } & $-0.293 * * *$ & $-0.283 * * *$ \\
\hline & $(0.0827)$ & $(0.0885)$ \\
\hline \multirow[t]{2}{*}{ GDP $(\log )$} & 0.1270 & 0.0490 \\
\hline & $(0.0904)$ & $(0.0958)$ \\
\hline \multirow[t]{2}{*}{ Trade (log) } & -0.0490 & 0.0511 \\
\hline & $(0.1930)$ & $(0.1920)$ \\
\hline \multirow[t]{2}{*}{ Population (log) } & $0.204 * * *$ & $0.205^{* * *}$ \\
\hline & $(0.0771)$ & $(0.0761)$ \\
\hline \multirow[t]{2}{*}{ Population Density (log) } & $-0.137 * * *$ & $-0.102 *$ \\
\hline & $(0.0525)$ & $(0.0525)$ \\
\hline \multirow[t]{2}{*}{ Age 65 and above (ratio) } & $0.518 * * *$ & $0.635 * * *$ \\
\hline & $(0.1660)$ & $(0.1640)$ \\
\hline \multirow[t]{2}{*}{ Latitude } & $0.0115^{* * *}$ & $0.0083 * *$ \\
\hline & $(0.0035)$ & $(0.0035)$ \\
\hline \multirow[t]{2}{*}{ Days since the first confirmed case } & -0.0092 & $-0.0104 *$ \\
\hline & $(0.0052)$ & $(0.0053)$ \\
\hline \multirow[t]{2}{*}{ Confirmed cases (log) } & $1.041 * * *$ & $1.043 * * *$ \\
\hline & $(0.0453)$ & $(0.0462)$ \\
\hline \multirow[t]{2}{*}{ Constant } & $-7.802 * * *$ & $-7.969 * * *$ \\
\hline & $(1.5290)$ & $(1.5270)$ \\
\hline Observations & 137 & 142 \\
\hline
\end{tabular}

$* * * \mathrm{p}<0.01, * * \mathrm{p}<0.05, * \mathrm{p}<0.1$

Kapoor et al. (2020) suggest another possibility that authoritarian governments manipulate COVID-19 death data. Their study recognizes the irregularity of the data and concludes that the manipulation process makes the data unnatural. Here we examine this possibility using the HRV Transparency Index (Hollyer et al. 2014) as an additional control. The HRV Transparency Project creates this index based on the WDI 
data. The project regards the missing values in the WDI data as the government's unwillingness to disclose its country's internal affairs. This index can be a proxy for data transparency.

Table 4: Determinants of COVID-19 Deaths with Transparency Index

\begin{tabular}{|c|c|c|}
\hline & (7) & (8) \\
\hline & NB & NB \\
\hline VARIABLES & Death Cases & Death Cases \\
\hline \multirow[t]{2}{*}{ Polity2 } & 0.0295 & \\
\hline & $(0.0181)$ & \\
\hline \multirow[t]{2}{*}{ Polyarchy } & & 0.6050 \\
\hline & & $(0.4350)$ \\
\hline \multirow[t]{2}{*}{ Transparency Index } & 0.0669 & 0.0800 \\
\hline & $(0.0687)$ & $(0.0664)$ \\
\hline \multirow[t]{2}{*}{ Physicians (log) } & $-0.257 * * *$ & $-0.251^{* *}$ \\
\hline & $(0.0988)$ & $(0.1030)$ \\
\hline \multirow[t]{2}{*}{ GDP (log) } & 0.1130 & 0.0665 \\
\hline & $(0.1130)$ & $(0.1170)$ \\
\hline \multirow{2}{*}{ Trade $(\log )$} & -0.0274 & 0.0075 \\
\hline & $(0.2290)$ & $(0.2280)$ \\
\hline \multirow[t]{2}{*}{ Population (log) } & $0.188^{*}$ & $0.171 *$ \\
\hline & $(0.0978)$ & $(0.0949)$ \\
\hline \multirow[t]{2}{*}{ Population Density (log) } & $-0.168 * * *$ & $-0.166 * * *$ \\
\hline & $(0.0593)$ & $(0.0591)$ \\
\hline \multirow[t]{2}{*}{ Age 65 and above (ratio) } & $0.512^{* *}$ & $0.519 * *$ \\
\hline & $(0.2040)$ & $(0.2080)$ \\
\hline \multirow[t]{2}{*}{ Latitude } & $0.0134 * * *$ & $0.0121^{* * *}$ \\
\hline & $(0.0039)$ & $(0.0037)$ \\
\hline \multirow[t]{2}{*}{ Days since the first confirmed case } & $-0.0136 * *$ & $-0.0132 * *$ \\
\hline & $(0.0060)$ & $(0.0059)$ \\
\hline \multirow[t]{2}{*}{ Confirmed cases (log) } & $1.023 * * *$ & $1.030 * * *$ \\
\hline & $(0.0526)$ & $(0.0524)$ \\
\hline \multirow[t]{2}{*}{ Constant } & $-6.470 * * *$ & $-6.251 * * *$ \\
\hline & $(2.0770)$ & $(2.0630)$ \\
\hline Observations & 111 & 112 \\
\hline
\end{tabular}

Table 4 shows the results of the analyses, including the Transparency Index as an additional control. Models 7 and 8 are the same as models 5 and 6, except for the Transparency Index. These models indicate that the political regime variables are no longer statistically significant with additional control; however, the Transparency Index is also not statistically significant. Cepaluni et al. (2020) also include this variable to 
control for the possibility of data manipulation. Nevertheless, in their study, the inclusion does not affect the robustness of the political regime variables. These results are different from those of their article at this point.

Models 7 and 8 show no statistical significance of both the political regime variables and the Transparency Index. These results imply that missing values affect the analyses. Twenty-six observations (countries) in Model 7 are dropped from Model 5 due to the Transparency Index's missing values, and thirty observations (countries) in Model 8 are dropped from Model 6 . This difference in observations can affect the results. Hollyer et al. (2014) "exclude any country that did not exist for the entirety of the 19802010 period" and "modern countries that are formed by the union of preexisting states during the 1980-2010 period - that is, Germany and Yemen" (419). The countries that were independent from the Soviet Union are excluded because of the first condition as they tend to be corrupt, which may systematically bias the results. Cepaluni et al. (2020) do not seem to recognize this potential problem. Then, the next analysis drops the observations in which the data on the Transparency Index are missing from models 5 and 6 to consider this possibility. Table 5 shows the results. 
Table 5: Determinants of COVID-19 Deaths without Transparency Index

\begin{tabular}{|c|c|c|}
\hline & (9) & (10) \\
\hline & NB & NB \\
\hline VARIABLES & Death Cases & Death Cases \\
\hline \multirow[t]{2}{*}{ Polity2 } & $0.0343 *$ & \\
\hline & $(0.0176)$ & \\
\hline \multirow[t]{2}{*}{ Polyarchy } & & 0.6940 \\
\hline & & $(0.4320)$ \\
\hline \multirow[t]{2}{*}{ Physicians (log) } & $-0.260 * * *$ & $-0.255^{* *}$ \\
\hline & $(0.0982)$ & $(0.1020)$ \\
\hline \multirow[t]{2}{*}{ GDP $(\log )$} & 0.1290 & 0.0779 \\
\hline & $(0.1120)$ & $(0.1180)$ \\
\hline \multirow[t]{2}{*}{ Trade (log) } & 0.0505 & 0.1160 \\
\hline & $(0.2150)$ & $(0.2120)$ \\
\hline \multirow[t]{2}{*}{ Population (log) } & $0.220 * *$ & $0.209 * *$ \\
\hline & $(0.0925)$ & $(0.0900)$ \\
\hline \multirow[t]{2}{*}{ Population Density (log) } & $-0.161 * * *$ & $-0.158^{* * *}$ \\
\hline & $(0.0599)$ & $(0.0599)$ \\
\hline \multirow[t]{2}{*}{ Age 65 and above (ratio) } & $0.596 * * *$ & $0.635^{* * *}$ \\
\hline & $(0.1850)$ & $(0.1840)$ \\
\hline \multirow[t]{2}{*}{ Latitude } & $0.0139 * * *$ & $0.0125 * * *$ \\
\hline & $(0.0039)$ & $(0.0037)$ \\
\hline \multirow[t]{2}{*}{ Days since the first confirmed case } & $-0.0149 * *$ & $-0.0149 * *$ \\
\hline & $(0.0059)$ & $(0.0058)$ \\
\hline \multirow[t]{2}{*}{ Confirmed cases (log) } & $1.033^{* * *}$ & $1.043 * * *$ \\
\hline & $(0.0518)$ & $(0.0517)$ \\
\hline \multirow[t]{2}{*}{ Constant } & $-7.516^{* * *}$ & $-7.524 * * *$ \\
\hline & $(1.7910)$ & $(1.7940)$ \\
\hline Observations & 111 & 112 \\
\hline
\end{tabular}

Models 9 and 10 are the same as models 5 and 6, except for the number of ob-

servations. These results indicate that the political regime variables are not statistically

significant at the conventional standard, although the Transparency Index is not con-

trolled for. These models strongly suggest that the missing countries on the Transpar-

ency Index affect the results. ${ }^{5}$ The next section examines the characteristics of these

countries.

${ }^{5}$ It is without a rational reason to exclude the countries in which the Transparency Index data are missing from the observations. On the other hand, the countries are systematically missing to some extent, according to Hollyer et al. (2014). In that sense, it is not totally unreasonable. 


\section{Extraordinarily Low Case Fatality Rate in Authoritarian Countries}

The case fatality rate (CFR) is the proportion of deaths from a particular disease compared to the total number of confirmed cases. This indicator is often used to assess the severity of the disease and is affected by the test numbers. In this sense, it means that if the rate is low, it is usually thought to be not due to the intervention by a government to reduce the confirmed cases but by other factors such as the level of medical infrastructure, human resources, nutrition condition, and so on after the infection. Table 6 shows the difference in CFR among the no-missing and missing countries on the Transparency Index divided by the level of Polity $2 .^{6}$

Table 6: Difference in CFR

\begin{tabular}{lrrrrr}
\hline CFR & Obs & \multicolumn{2}{r}{ Mean Std. Dev. } & Min & Max \\
\hline All countries & 164 & 2.9893 & 2.96853 & 0 & 16.2156 \\
Data Missing Countries & 31 & 1.81081 & 1.38687 & 0 & 5.46985 \\
Data Missing Countries (Polity2<6) & 12 & 1.01202 & 0.73247 & 0 & 2.4319 \\
Data Missing Countries (Polity2<0) & 8 & 0.62675 & 0.45111 & 0 & 1.39734 \\
\hline
\end{tabular}

This table reveals an astonishing tendency. The lower the value of Polity2, the lower the CFR in the missing countries, which is improbable. Graphs 2 through 5 show the incredible patterns graphically. In Graph 2, the fitted line is moderately positive in the countries with no missing data on the Transparency Index, and the correlation

6 Yemen is excluded from the data as an outlier because the country deviates far from the other variables. Its CFR is 28.21553 . 
coefficient is 0.2811 . On the other hand, in Graph 3, the relationship between Polity2

and CFR is clearly positive in the data missing countries on the Transparency Index, and the correlation coefficient is 0.5793 . The same patterns can be seen in graphs 4 and 5 .

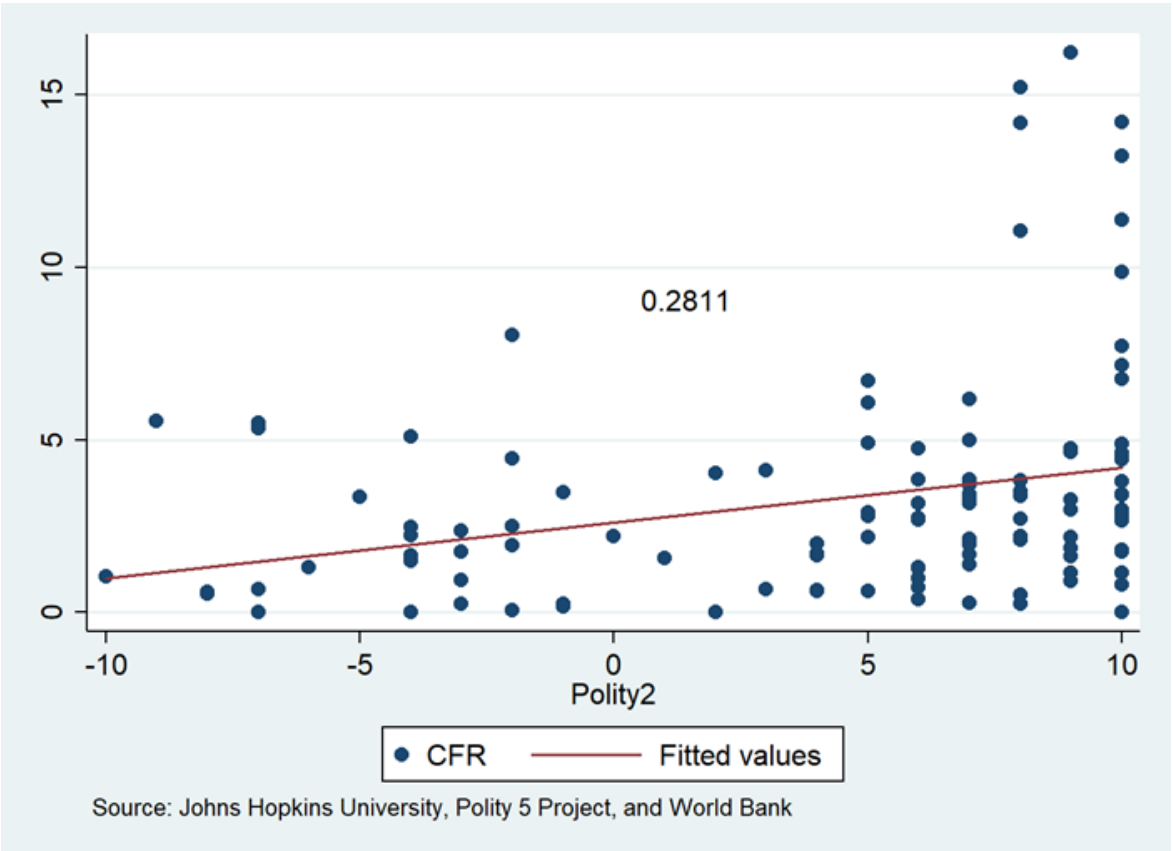

Graph 2: Relationship between Polity2 and CFR for Transparency Index non-missing countries 


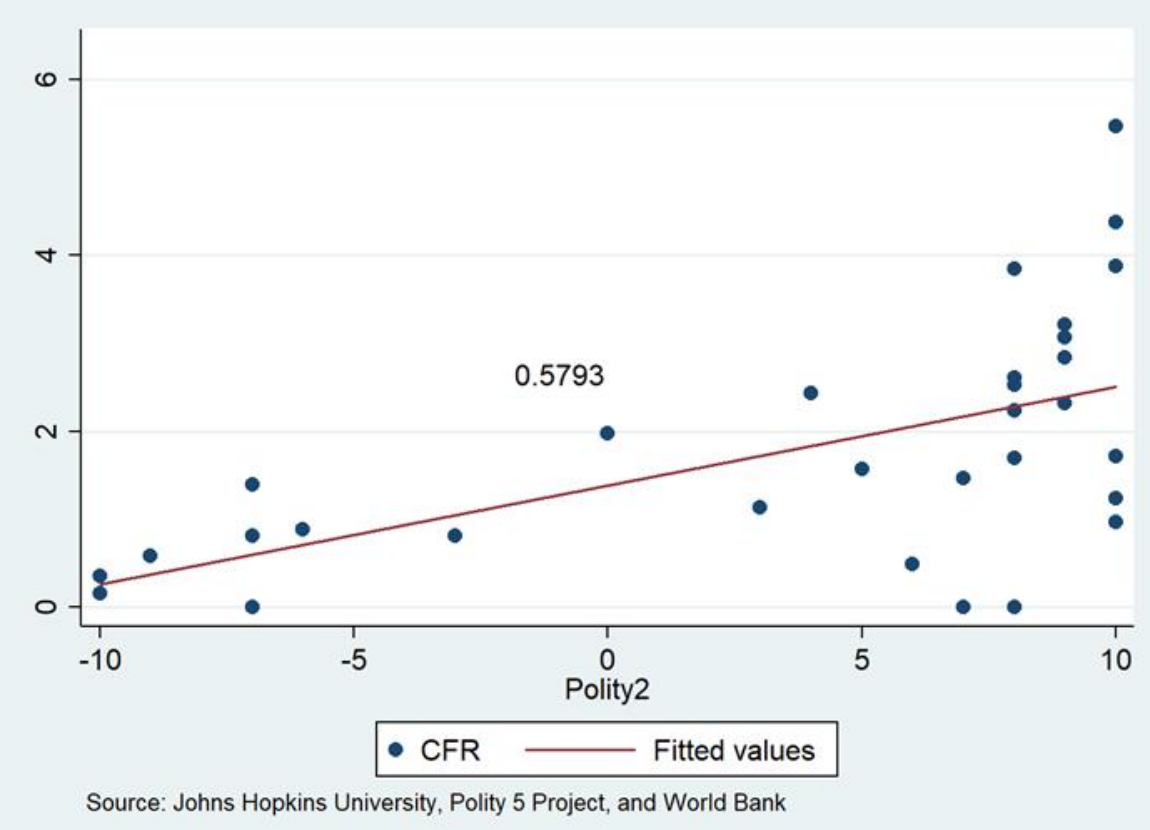

Graph 3: Relationship between Polity2 and CFR for Transparency Index missing countries

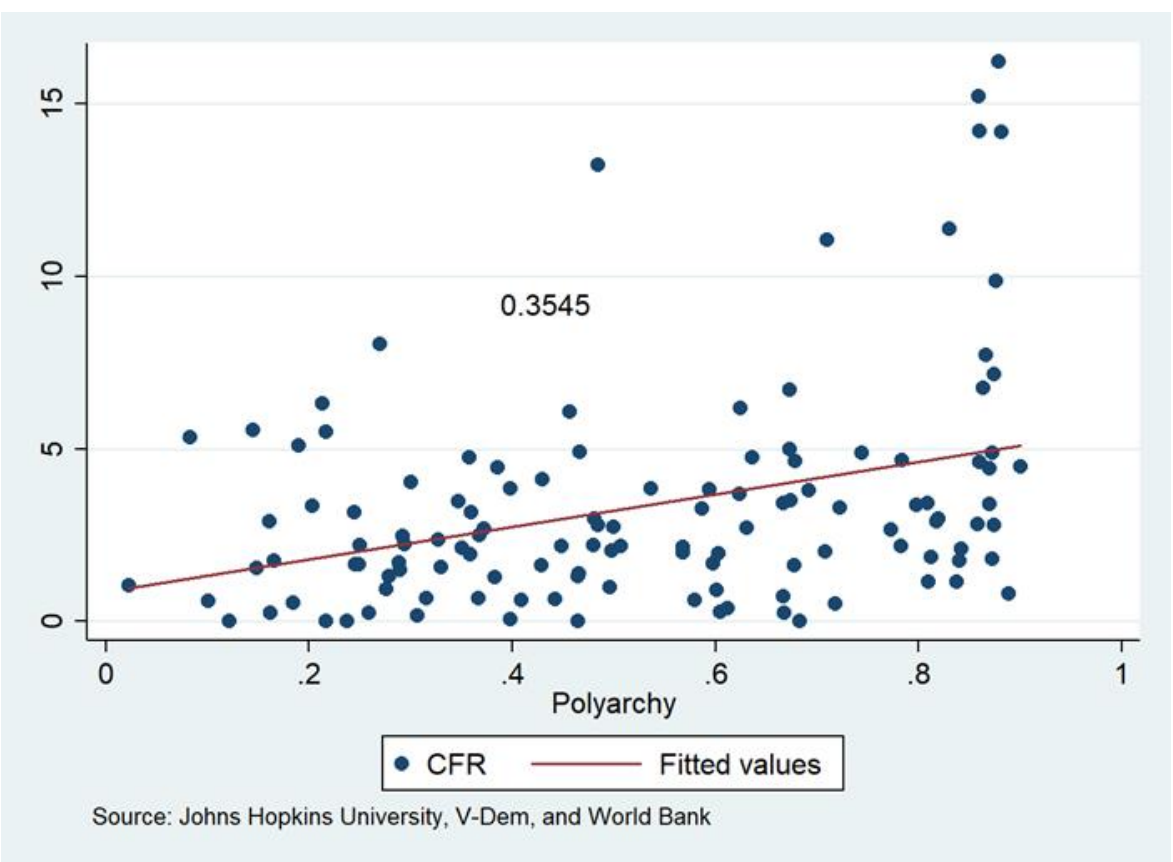

Graph 4: Relationship between Polyarchy and CFR for Transparency Index non-missing countries 


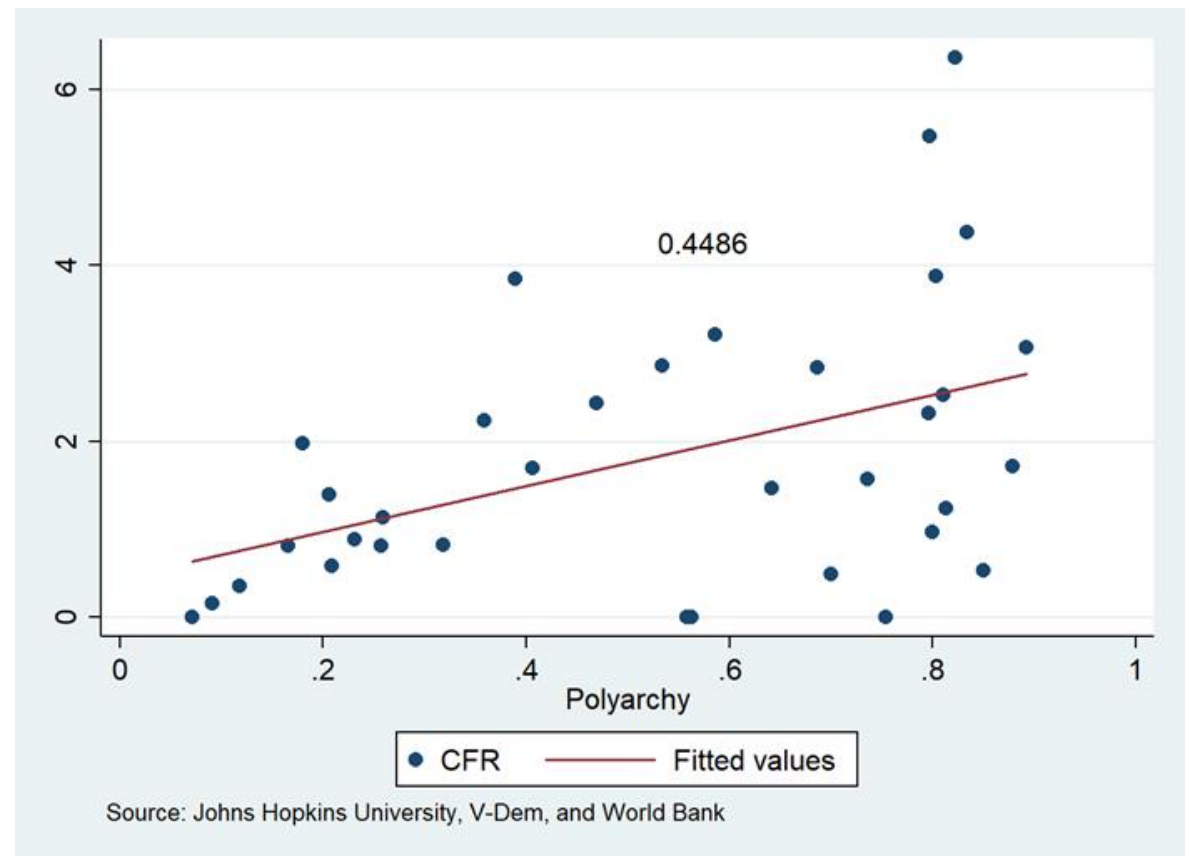

Graph 5: Relationship between Polyarchy and CFR for Transparency Index missing countries

These graphs clearly reveal that the lower the level of Polity2, the lower the CFR, especially in the data-missing countries. Additional regression results also support these patterns. Table 7 shows the relationship between political regimes and COVID-19 deaths and CFR in the data-missing countries. The dependent variables in models 11 through 14 are the number of deaths. The political regime variables are positively correlated with the number of deaths at a statistically significant level. The dependent variables in models 15 and 18 are the CFR. These models also confirm a similar relationship, except for model 18. These results are tough to interpret. However, the variable of physicians is not statistically significant in all these models, and the confirmed cases continue to be significant in all the models in which the variable is included. 


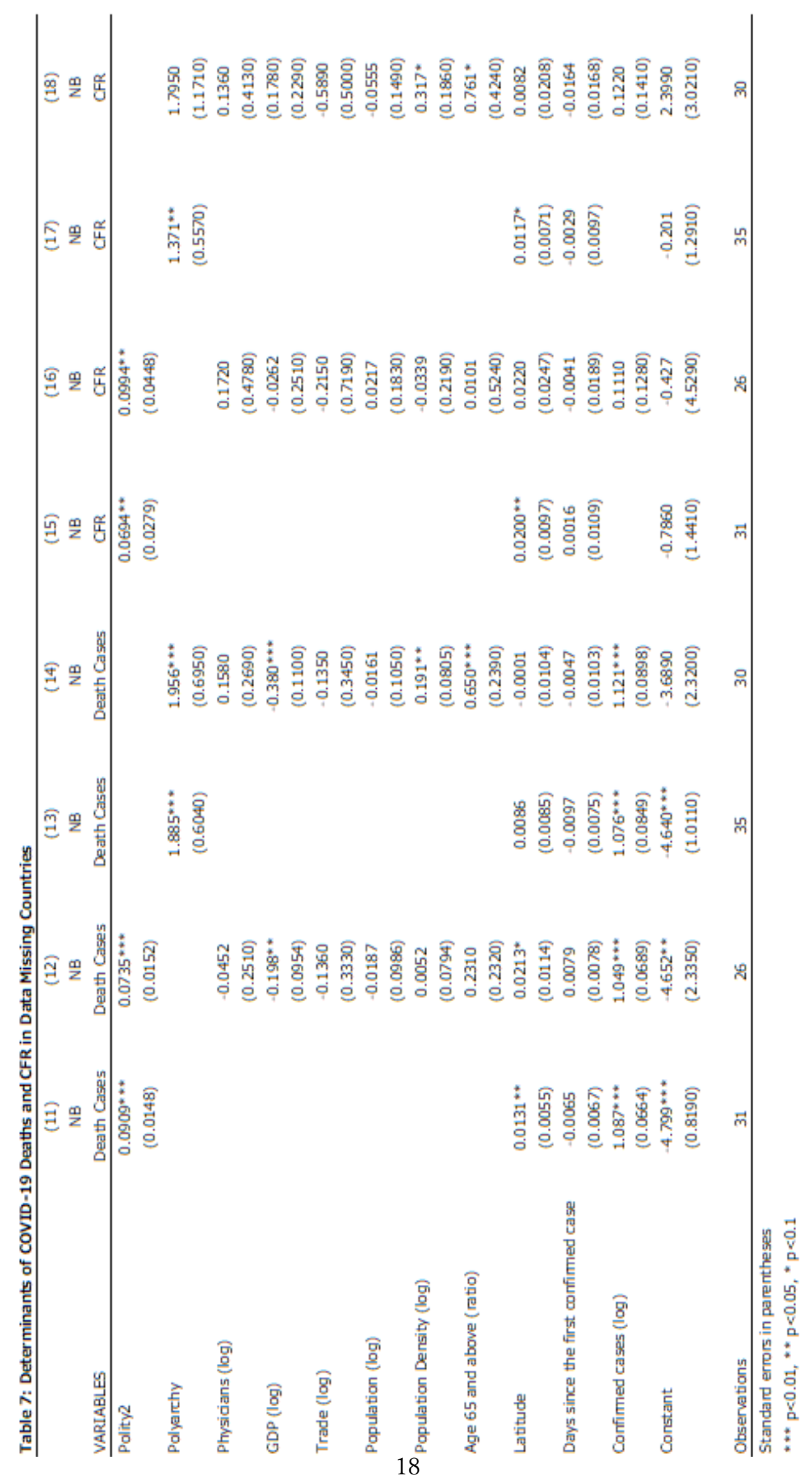


These results suggest that a factor other than the government's interventions or medical systems possibly affects the COVID-19 deaths.

In conclusion, it is strongly suspected that some authoritarian countries, especially in the data missing countries on the Transparency Index, manipulate data on COVID-19-related deaths. Kapoor et al. (2020) are more persuasive than other studies such as Cepaluni et al. (2020), which argue that authoritarian countries have been able to manage the COVID-19 problem more effectively.

\section{Changing Trends}

The analyses above are based on the data available on July 31, 2020. The situation seems to change now in October. Table 8 shows the results of the relationship between the political regime and COVID-19 deaths and CFR with the latest available data (October 10, 2020). ${ }^{7}$ Models 19 through 22 reveals that both Polity2 and Polyarchy are no longer statistically significant. These results mean that the (superficial) advantage of authoritarian countries is now diminished.

The reason for this is unknown. Authoritarian leaders may no longer attempt to manipulate the data. Anyway, the argument that authoritarian countries have succeeded

7 The descriptive statistics are in Appendix 2. 
in reducing COVID-19 deaths much better than democratic countries is no longer persuasive now. The tradeoff hypothesis between freedom and health is dubious.

Table 8: Determinants of COVID-19 Deaths and CFR (as of October 10, 2020)

\begin{tabular}{|c|c|c|c|c|}
\hline & (19) & (20) & (21) & (22) \\
\hline & NB & NB & NB & NB \\
\hline VARIABLES & Death Cases & Death Cases & CFR & CFR \\
\hline \multirow[t]{2}{*}{ Polity2 } & 0.0176 & & 0.0197 & \\
\hline & $(0.0133)$ & & $(0.0140)$ & \\
\hline \multirow[t]{2}{*}{ Polyarchy } & & 0.5420 & & $0.688^{*}$ \\
\hline & & $(0.3390)$ & & $(0.3750)$ \\
\hline \multirow{2}{*}{ Physicians (log) } & $-0.278 * * *$ & $-0.261 * * *$ & $-0.240 * * *$ & $-0.217 * *$ \\
\hline & $(0.0806)$ & $(0.0828)$ & $(0.0825)$ & $(0.0845)$ \\
\hline \multirow[t]{2}{*}{ GDP (log) } & -0.0097 & -0.0453 & 0.0756 & 0.0186 \\
\hline & $(0.0772)$ & $(0.0810)$ & $(0.0833)$ & $(0.0895)$ \\
\hline \multirow[t]{2}{*}{ Trade (log) } & 0.0171 & 0.0279 & 0.0557 & 0.0609 \\
\hline & $(0.1590)$ & $(0.1590)$ & $(0.1750)$ & $(0.1700)$ \\
\hline \multirow[t]{2}{*}{ Population (log) } & $0.172^{* *}$ & $0.174 * * *$ & $0.231 * * *$ & $0.233 * * *$ \\
\hline & $(0.0670)$ & $(0.0653)$ & $(0.0638)$ & $(0.0594)$ \\
\hline \multirow[t]{2}{*}{ Population Density (log) } & $-0.139 * * *$ & $-0.114 * *$ & $-0.113^{* *}$ & $-0.0971 * *$ \\
\hline & $(0.0453)$ & $(0.0443)$ & $(0.0489)$ & $(0.0473)$ \\
\hline \multirow[t]{2}{*}{ Age 65 and above (ratio) } & $0.594 * * *$ & $0.596^{* * *}$ & $0.453 * *$ & $0.453^{* *}$ \\
\hline & $(0.1570)$ & $(0.1500)$ & $(0.1850)$ & $(0.1840)$ \\
\hline \multirow[t]{2}{*}{ Latitude } & 0.0015 & 0.0002 & 0.0019 & 0.0014 \\
\hline & $(0.0030)$ & $(0.0029)$ & $(0.0030)$ & $(0.0029)$ \\
\hline \multirow[t]{2}{*}{ Days since the first confirmed case } & -0.0043 & -0.0048 & -0.0052 & -0.0055 \\
\hline & $(0.0046)$ & $(0.0046)$ & $(0.0047)$ & $(0.0046)$ \\
\hline \multirow[t]{2}{*}{ Confirmed cases (log) } & $1.065^{* * *}$ & $1.060 * * *$ & & \\
\hline & $(0.0443)$ & $(0.0428)$ & & \\
\hline \multirow[t]{2}{*}{ Constant } & $-7.335^{* * *}$ & $-7.251^{* * *}$ & $-3.663 * *$ & $-3.506 * *$ \\
\hline & -1.283 & $(1.2660)$ & $(1.5340)$ & $(1.4440)$ \\
\hline Observations & 137 & 142 & 137 & 142 \\
\hline
\end{tabular}

Standard errors in parentheses

*** $\mathrm{p}<0.01, * * \mathrm{p}<0.05, * \mathrm{p}<0.1$

\section{Conclusion}

A great number of people have been suffering and dying of COVID-19. Some scholars

argue that the pandemic has severely damaged democratic countries, mainly because

democratic countries cannot intervene in citizens' lives in the same way as authoritarian

countries. On the other hand, another study challenges this view and suggests that au-

thoritarian countries manipulate data on COVID-19-related death. This paper examines 
which view is more persuasive using cross-national data and reveals statistical evidence that authoritarian countries are likely to manipulate the data. This result implies that the tradeoff between freedom and health is superficial and misleading. It is probable that authoritarian countries only overstate their performance; nevertheless, authoritarian states can strengthen citizens' support for their governments through the COVID-19 pandemic by successfully manipulating the data.

This study has some limitations. For example, Cepaluni et al. (2020) and Cheibub et al. (2020) utilize daily data, which can make a more nuanced analysis possible to capture daily fluctuations in the prevalence of COVID-19 as well as the government's interventions. However, almost all other variables included in the analysis are yearly data, and it is not easy to determine which are more appropriate for analyzing the phenomena.

Another caution is that this study does not consider the effects of the number of tests. It may be possible that authoritarian countries conduct much more tests than democratic states, and that may affect the results. But only the 87 countries' test data are available. ${ }^{8}$ The number of observations is too small, much fewer than the

8 Our World in Data, https://ourworldindata.org/coronavirus-testing, accessed on October 18, 2020 . 
Transparency Index data. This study regards the inclusion of the data into the analyses as meaningless in that aspect. 


\section{References}

Cepaluni, G., Dorsch, M., and Branyiczki, R. (2020), "Political Regimes and Dea ths in the Early Stages of the COVID-19 Pandemic," (April 27, 2020). Available at SSRN: https://ssrn.com/abstract=3586767 or http://dx.doi.org/1 0.2139/ssrn.3586767(2020/09/11)

Cheibub, J. A., Hong, J. Y. J., and Przeworski, A. (2020) "Rights and Deaths: Government Reactions to the Pandemic," (July 7, 2020). Available at SS RN: https://ssrn.com/abstract=3645410 or http://dx.doi.org/10.2139/ssrn.3645 410

Gerring, J., Knutsen, C. H., Mguire, M., Skaaning, S., Teorell, J., and Coppedge, M. (2020) "Democracy and human development: issues of conceptualizat ion and measurement," Democratization. DOI: 10.1080/13510347.2020.1818 721

Hale, T., Webster, S., Petherick, A., Phillips, T., and Kira, B. (2020) "Oxford C OVID 19 Government Response Tracker", Blavatnik School of Governme nt. Data use policy: Creative Commons Attribution CC BY standard. Ava ilable at https://www.bsg.ox.ac.uk/research/research projects/coronavirus gov ernment response tracker\#data. Accessed on July 17, 2020.

Harari, Y. N. (2020) “The World after Coronavirus" Financial Times, March 20, 2020, https://www.ft.com/content/19d90308-6858-11 ea-a3c9-1fe6fedcca75. Accessed on Octorber 11, 2020.

Hollyer, J. R., Rosendorff, B. P., and Vreeland, J. R. (2014) "Measuring Transpar ency" Political Analysis 22: 413-434.

Kapoor, M., Malani, A., Ravi, S., and Agrawal, A. (2020) "Authoritarian Govern ments Appear to Manipulate COVID Data," arXiv, https://arxiv.org/abs/20 07.09566(2020/09/11)

Karáth, Kata (2020) "Covid-19: How does Belarus have one of the lowest death rates in Europe?" BMJ 2020;370:m3543.

Koyama, M., (2020) "Epidemic Disease and the State" Works in Progress, Augus t 20, 2020, https://www.worksinprogress.co/issue/epidemic-disease-and-the-st ate/ Accessed on Octorber 11, 2020.

Wang, Y., Mechkova, V., \& Andersson, F. (2019) "Does Democracy Enhance He alth? New Empirical Evidence 1900-2012" Political Research Quarterly 7 2: 554-569. 
Appendix 1: Descriptive Statistics

\begin{tabular}{lrrrrr}
\hline \multicolumn{1}{c}{ Variable } & Obs & Mean & Std. Dev. & Min & Max \\
\hline Confirmed Cases & 165 & 104156.600 & 429607.10 & 14 & 4495014 \\
Confirmed Deaths & 165 & 4068.2060 & 15395.0300 & 0 & 152070 \\
Polity2 & 153 & 4.4052 & 5.9686 & -10 & 10 \\
Polyarchy & 159 & 0.5262 & 0.2499 & 0.023 & 0.9 \\
Transparency Index & 123 & 0.9545 & 1.9991 & -7 & 6 \\
Doctors per 1000 (log) & 157 & -0.0037 & 1.4366 & -4.2687 & 2.1308 \\
GDP per capita (log) & 158 & 8.6717 & 1.4925 & 5.3509 & 11.6146 \\
Trade Ratio to GDP (log) & 155 & 4.3442 & 0.5162 & 3.2729 & 5.9442 \\
Population (log) & 164 & 16.1582 & 1.7680 & 10.4278 & 21.0545 \\
Population Density (log) & 161 & 4.2378 & 1.4914 & -1.9915 & 8.9813 \\
Age 65 and above Ratio (log) & 160 & 1.9089 & 0.7669 & 0.0816 & 3.3170 \\
Latitude & 164 & 19.6893 & 24.6799 & -40.9006 & 64.9631 \\
Days since First Confirmed Case & 165 & 147.9939 & 19.8849 & 78 & 213 \\
Confirmed Cases (log) & 165 & 8.9942 & 2.5021 & 2.6391 & 15.3185 \\
\hline
\end{tabular}

Appendix 2: Descriptive Statistics (as of October 10, 2020)

\begin{tabular}{lrrrrr}
\hline \multicolumn{1}{c}{ Variable } & Obs & Mean & Std. Dev. & Min & Max \\
\hline Confirmed Cases & 165 & 222013.1 & 902507.6 & 16 & 7664676 \\
Confirmed Deaths & 165 & 6452.291 & 23478.44 & 0 & 213787 \\
CFR & 165 & 2.5689 & 2.7897 & 0 & 29 \\
\hline
\end{tabular}

